\title{
Mechanical Properties of Natural Rubber Nanocomposites Filled with Thermally Treated Attapulgite
}

\author{
Jihu Wang ${ }^{1,2}$ and Dajun Chen ${ }^{1}$ \\ ${ }^{1}$ College of Material Science and Engineering, Donghua University, Shanghai 201620, China \\ ${ }^{2}$ College of Chemistry and Chemical Engineering, Shanghai University of Engineering Science, Shanghai 201620, China \\ Correspondence should be addressed to Dajun Chen; cdj@dhu.edu.cn
}

Received 20 July 2013; Accepted 19 August 2013

Academic Editor: Shanfeng Wang

Copyright (c) 2013 J. Wang and D. Chen. This is an open access article distributed under the Creative Commons Attribution License, which permits unrestricted use, distribution, and reproduction in any medium, provided the original work is properly cited.

\begin{abstract}
Natural rubber (NR) nanocomposites were prepared in a double-roller plasticator mixer with purified attapulgite (PAT) or modified attapulgite, which was treated at $450^{\circ} \mathrm{C}$ (PAT-450) and $850^{\circ} \mathrm{C}$ (PAT-850) for two hours. The structures of the pristine, purified, and modified attapulgite were characterized by FTIR, TEM, XRD, and BET. The results indicated that the structure of attapulgite changed with the increased temperature. The effects of the PAT treatment and content on the mechanical properties of the NR nanocomposites were also investigated. The results showed that AT increased curing process of natural rubber. A significant improvement in the tensile strength, wearability, and solvent resistance of the nanocomposites was observed with the addition of different types of attapulgite as compared to those of pure NR. Scanning electron microscope images showed that the filler was located at the interface, which induced compatibilization in the immiscible blends. Thermogravimetric analysis revealed a significant improvement in the thermal stability of the NR/PAT nanocomposites.
\end{abstract}

\section{Introduction}

Polymer nanocomposites have received considerable attention in recent years because of their diverse nanometersized filler particles and a series of special performance. Carbon is a traditional filler because of its ability to reinforce rubber [1-3]. Due to the large amount of mill dust produced during the rubber processing and thus its black color, the production application is limited. The other important filler is silica which can improve the performance of polymer nanocomposites $[4,5]$. But the price is very high. Thus, nanoscale fillers such as clay particles [6,7] (e.g., kaolin [8,9], montmorillonite [10, 11], attapulgite [12-14], mica [15], etc.) have been introduced and subsequently used in the rubber industry.

Attapulgite (AT) is a natural clay mineral with the ideal structural formula of $\mathrm{Mg}_{5} \mathrm{Si}_{8} \mathrm{O}_{20}(\mathrm{OH})_{2}\left(\mathrm{OH}_{2}\right)_{4} \cdot 4 \mathrm{H}_{2} \mathrm{O}$; this formula was first proposed by Bradley in 1940 [16]. AT has attracted considerable attention because of its fiberlike structural morphology, particularly in the adsorption of organics on the clay surfaces [17-19]. This nanostructure results in the outstanding attributes of $\mathrm{AT}$ as a reinforcement and improves the mechanical properties of materials [2022]. To improve the compatibility between inorganic clay and organic polymer, different coupling agents and acids are used to modify AT surface [23-25]. In situ polymerization is another method frequently used to modify AT [26, 27].

Recently, the heat treatment technique is considered a very important way to modify attapulgite which will change the structure of attapulgite. Water, hydroxyl group, and impurities in attapulgite disappeared after being modified at different temperature. The activity of heat treated attapulgite was improved.

Lai et al. [28] reported that thermally treated attapulgite at different temperature was superior to untreated attapulgite in enhancing the wear resistance of Polytetrafluoroethene (PTFE). They explained that this behavior was attributed to the effect of heat, improving surface properties of attapulgite and removing water in attapulgite, which resulted in strengthening interactive force between attapulgite and PTFE. Lai et al. [29] used palygorskite to prepared silica powder at different temperature. When the optimum calcination temperature was at $560^{\circ} \mathrm{C}$, the silica content, the whiteness, and the specific surface area of the product were $85 \%, 92 \%$, 
TAble 1: Degradation of AT at different temperatures.

\begin{tabular}{lccc}
\hline $\mathrm{Mg}_{8} \mathrm{Si}_{12} \mathrm{O}_{30}(\mathrm{OH})_{4} \cdot\left(\mathrm{H}_{2} \mathrm{O}\right)_{4} \cdot 8 \mathrm{H}_{2} \mathrm{O}$ & Veronika & Tartaglione & $\mathrm{Chen}$ \\
$\rightarrow \mathrm{Mg}_{8} \mathrm{Si}_{12} \mathrm{O}_{30}(\mathrm{OH})_{4} \cdot\left(\mathrm{H}_{2} \mathrm{O}\right)_{4}+8 \mathrm{H}_{2} \mathrm{O}$ & $\sim 92^{\circ} \mathrm{C}$ & $T_{\max }=110^{\circ} \mathrm{C}$ & $65^{\circ} \mathrm{C}$ \\
$\rightarrow \mathrm{Mg}_{8} \mathrm{Si}_{12} \mathrm{O}_{30}(\mathrm{OH})_{4} \cdot\left(\mathrm{H}_{2} \mathrm{O}\right)_{2}+2 \mathrm{H}_{2} \mathrm{O}$ & $\sim 130^{\circ} \mathrm{C}$ & $T_{\max }=325^{\circ} \mathrm{C}$ & $98^{\circ} \mathrm{C}$ \\
$\rightarrow \mathrm{Mg}_{8} \mathrm{Si}_{12} \mathrm{O}_{30}(\mathrm{OH})_{4}+2 \mathrm{H}_{2} \mathrm{O}$ & $\sim 249^{\circ} \mathrm{C}$ & $T_{\max }=535^{\circ} \mathrm{C}$ & 230 to $481^{\circ} \mathrm{C}$ \\
$\rightarrow \mathrm{MgSiO}_{3}+4 \mathrm{SiO}_{2}+2 \mathrm{H}_{2} \mathrm{O}$ & $\sim 434^{\circ} \mathrm{C}$ & $T>780^{\circ} \mathrm{C}$ & $595^{\circ} \mathrm{C}$ \\
\hline
\end{tabular}

and $308 \mathrm{~m}^{2} / \mathrm{g}$, respectively. The silica still maintained the fibrous morphology of palygorskite besides a few spherical particles of 10-20 nm in diameter. Gan et al. [30] showed that the natural palygorskite was treated by thermal activation over $100-1000^{\circ} \mathrm{C}$ for $2 \mathrm{~h}$. The thermal activation increased the phosphate sorption capacity, and the highest phosphate sorption capacity occurred at $700^{\circ} \mathrm{C}$. Thermal treatment resulted in significant changes in crystal structure and physicchemical properties of palygorskite.

Vágvölgyi et al. [31] studied the thermal decomposition of AT using a combination of dynamic and controlled rate thermal analyses. Lokanatha et al. [32] studied the decomposition of AT. The R.D.F. technique successfully explained the AT structural transformation accompanied dehydration. Frost et al. $[33,34]$ analyzed the dehydration and dehydroxylation of AT by investigating the thermal degradation via near-infrared and mid-infrared emission spectroscopy over the $100^{\circ} \mathrm{C}$ to $700^{\circ} \mathrm{C}$ temperature range. The decomposition processes of attapulgite at different temperatures achieved by Vágvölgyi et al. [31], Tartaglione et al. [35], and Chen et al. [36] are shown in Table 1. The degradation processes and products of AT are the same at different degradation temperatures.

To the best of our knowledge, no study has been conducted on the mechanical properties of natural rubber (NR) nanocomposites filled with AT and modified at different temperatures. In this paper, AT, either purified or modified, was added to NR in different ratios. The properties of the resulting nanocomposites were then investigated. This study aims to determine the effects of AT treatment and filler contents on the mechanical properties of nanocomposites.

\section{Experimental Section}

2.1. Materials. Attapulgite was provided by Nanjing Yuanda Clay Co. Ltd. Sodium pyrophosphate decahydrate $\left(\mathrm{Na}_{4} \mathrm{P}_{2} \mathrm{O}_{7} \cdot 10 \mathrm{H}_{2} \mathrm{O}\right)$ was purchased from Sinopharm Chemical Reagent Co. Ltd. NR was purchased from Hainan. Zinc oxide $(\mathrm{ZnO})$, stearic acid (HSt), 2-mercaptobenzothiazole (accelerator $\mathrm{M}$ ), diphenyl guanidine (accelerator DM), tetramethylthiuram bisulfide (accelerator TMTD), N-phenyl-2naphthylamine (antiaging agent $\mathrm{D})$, sulfur (S), and other chemical agents were commercially available.

2.2. Purified and Thermally Treated AT. To remove the impurities in natural AT, $200 \mathrm{~g}$ of pulverized pristine AT was immersed in $800 \mathrm{~g}$ distilled water to obtain a homogeneous suspension liquid. A total of $6 \mathrm{~g}$ of $\mathrm{Na}_{4} \mathrm{P}_{2} \mathrm{O}_{7} \cdot 10 \mathrm{H}_{2} \mathrm{O}$ was then added to the solution under high mechanical stirring for $30 \mathrm{~min}$. The suspension of the solution was filtered after
$24 \mathrm{~h}$ at room temperature. The solids were then heated in a vacuum oven for $24 \mathrm{~h}$ at $80^{\circ} \mathrm{C}$ and slowly cooled to room temperature under vacuum to remove moisture. The solids were milled using a ball grinder and subsequently designated as purified attapulgite (PAT).

PAT was treated at 450 and $850^{\circ} \mathrm{C}$ for $2 \mathrm{~h}$ in a muffle furnace. The heat-treated AT was then obtained and pulverized. The samples were designated as PAT-450 and PAT-850.

2.3. Nanocomposite Preparation. In accordance with the experimental formula presented in Table 2, nanocomposites were prepared on a double-roller plasticator with an outside diameter of $470 \mathrm{~mm}$ at room temperature. The rotors operated at a speed ratio of $1: 1.4$. The vulcanization agents were previously added to the elastomer. Different amounts of the filler compatibilizer were then added $[0.5,1,3,5,7$, and 10 parts per hundred rubbers (phr)]. Finally, sulfur was added. The nanocomposite of NR/PAT- $0.5 \%$ means natural rubber filled with 0.5 phr PAT; other nanocomposites were defined similarly.

An oscillating disc rheometer (MDR-2000E, Liyuan, China) was used in a standardized method to measure the curing characteristics of the NR nanocomposites at $150^{\circ} \mathrm{C}$. The oscillation exerts a shear strain on the sample, and the torque required to oscillate the sample is proportional to the shear modulus of the rubber. The vulcanization time of the nanocomposites corresponds to the optimum cure time $t_{90}$, which is derived from the curing curves under $15 \mathrm{MPa}$ pressures on an electrically heated press. The sheeted compounds and abrasion loss samples were placed at $20^{\circ} \mathrm{C}$ for $24 \mathrm{~h}$ prior to testing.

2.4. Characterization. AT combined with oven-dried: spectroscopy grade potassium bromide was finely ground for several minutes under an infrared lamp and was then pressed into a disc. The spectroscopy of each sample was recorded using a Fourier transform infrared spectrometer (FTIR) from $4000 \mathrm{~cm}^{-1}$ to $400 \mathrm{~cm}^{-1}$ at a resolution of $2 \mathrm{~cm}^{-1}$ (Nicolet DosX, Nicolet, America).

The AT powder was dispersed in deionized water under ultrasonic vibration for approximately $30 \mathrm{~min}$ and was then deposited on a copper grid. The morphology of the samples was observed using transmission electron microscopy (TEM) measurements (JEM-2100, JEOL, Japan).

The AT powder was scanned from $2 \theta=5^{\circ}$ to $70^{\circ}$ at a rate of $2^{\circ} /$ min using an X-ray diffractometer (XRD) (X'Pert PRO, PANalytical, Holland) with $\mathrm{Cu} \mathrm{K}_{\alpha}$ radiation $(\lambda=$ $0.15415 \mathrm{~nm}$ ) operating under a tube voltage of $45 \mathrm{kV}$ and a tube current of $40 \mathrm{~mA}$. 
TABLE 2: Formulations of the rubber compounds.

\begin{tabular}{lc}
\hline Ingredients & $(\mathrm{phr})$ \\
\hline $\mathrm{NR}$ & 100 \\
$\mathrm{HSt}$ & 1 \\
$\mathrm{ZnO}$ & 5 \\
Accelerator M & 1.2 \\
Accelerator DM & 0.3 \\
Accelerator TMTD & 0.2 \\
Antiaging agent D & 1 \\
PAT, PAT-450, or PAT-850 & $0.5,1,3,5,7,10$ \\
S & 2.5 \\
\hline
\end{tabular}

The specific surface area of AT was determined by obtaining the nitrogen adsorption-desorption isotherms at $77 \mathrm{~K}$ using a conventional high volumetric system consisting of a TriStar 3000 surface area analyzer (Micromeritics, USA). The Brunauer-Emmett-Teller (BET) method was used for the corresponding calculations.

Tensile tests of the nanocomposites were performed at room temperature using computer-controlled universal testing machines (GT-TCS-2000, Gotech, Taiwan). The tensile speed was $500 \mathrm{~mm} \cdot \mathrm{min}^{-1}$. The test samples were prepared in a standard dumbbell shape, and all measurements were repeated five times until a median value was obtained.

The abrasion resistance of the vulcanized rubber nanocomposites was determined using an Akron machine (GT-7012-A, Gotech, Taiwan). The abrasion volume is equal to the sample loss weight divided by the sample's density.

Swelling tests were conducted by using $0.5 \mathrm{~g}$ vulcanized nanocomposites, which were immersed in an excess of toluene solution in brown glass bottles until equilibrium was achieved. The swelling indices of the nanocomposites were calculated using the ratio of the weight changes in the samples.

The fracture surfaces of tensile specimens were sprayed with $\mathrm{Au}$ to make them conductive. SEM (S-2150, Hitachi, Japan) was used to determine the morphology of the fracture surfaces.

The thermal stability of the nanocomposites was determined using thermogravimetric analysis (TGA, PT1000, Linseis, Germany). The tests were performed at $20^{\circ} \mathrm{C} \cdot \mathrm{min}^{-1}$ under nitrogen (flow rate, $5 \times 10^{-7} \mathrm{~m}^{3} \cdot \mathrm{s}^{-1}$ ). The samples were then placed in open silica pans.

\section{Results and Discussion}

3.1. Fourier Transforms Infrared Spectroscopy. Figure 1 shows the FTIR spectra of AT, PAT, PAT-450, and PAT-850. The spectra show three significant changes. Four hydroxylstretching frequencies of natural AT were observed at 3614, 3581,3552 , and $3419 \mathrm{~cm}^{-1}$. The band at $3614 \mathrm{~cm}^{-1}$ is attributed to hydroxyls coordinated with the magnesium [33]. Bands at 3581 and $3552 \mathrm{~cm}^{-1}$ are attributed to the symmetric and antisymmetric stretching modes of molecular water coordinated with the magnesium at the edges of the channels [33]. The

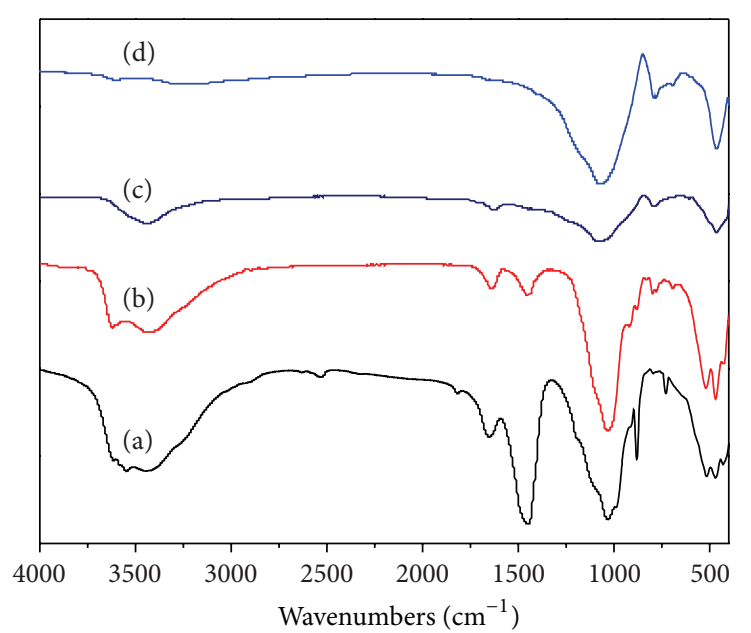

FIGURE 1: Fourier transforms infrared (FTIR) spectra of (a) AT, (b) PAT, (c) PAT-450, and (d) PAT-850.

band at $3419 \mathrm{~cm}^{-1}$ is due to the water in the AT structure [34]. The hydroxyl stretching vibrations of absorbed water is at $1650 \mathrm{~cm}^{-1}$ [37]. The band at $1450 \mathrm{~cm}^{-1}$ is due to the stretching vibration of magnesium oxygen. The bands from $986 \mathrm{~cm}^{-1}$ to $692 \mathrm{~cm}^{-1}$ are due to hydroxyl deformation [37].

Compared with that of pristine AT, the FTIR spectrum of PAT did not changed except that the intensity of the band at $1450 \mathrm{~cm}^{-1}$ was weaker and at $1819 \mathrm{~cm}^{-1}$ was disappeared. It might be attributed to impurities which were presented in natural attapulgite.

The intensities of the AT bands at 3614, 3581, 3552, 1650, 1450 , and $922 \mathrm{~cm}^{-1}$ to $692 \mathrm{~cm}^{-1}$ decreased, even some bands disappeared when the treatment temperature was set at $450^{\circ} \mathrm{C}$ [38]. The dehydration of AT is followed by the loss of the peak intensity of the hydroxyl bands of water. Dehydroxylation is followed by the decrease in the peak intensity of the band $3419 \mathrm{~cm}^{-1}$.

The FTIR spectra of the hydroxyl stretching bands of AT disappeared when the temperature was set at $850^{\circ} \mathrm{C}$. The figure clearly shows the decrease in the intensity of these bands as the temperature increases. However, the band at $1034 \mathrm{~cm}^{-1}$ remains prominent and is attributed to $\mathrm{Si}-\mathrm{O}$ stretching even at $850^{\circ} \mathrm{C}$ [39]. The intensities of the 692 and $465 \mathrm{~cm}^{-1}$ bands are also maintained. These two bands are not lost because they are associated with the $\mathrm{OH}$ translation peak and $\mathrm{O}-\mathrm{Si}-\mathrm{O}$ bend vibration peak, respectively [40].

3.2. Transmission Electron Microscopy. Figure 2 shows the TEM images of AT, PAT, PAT-450, and PAT-850. Numerous impurities are present in natural AT, which exhibits a fibrous structure. However, some fibers agglomerate to form AT rods (Figure 2(a)). After purification (Figure 2(b)), the TEM micrograph shows that the AT particles are highly dispersed as individual rod-like structures with an average diameter of $20 \mathrm{~nm}$ and a length of $500 \mathrm{~nm}$ to $1000 \mathrm{~nm}$, without any aggregation. But the AT structure was changed with the treatment at higher temperature. There were two morphologies 

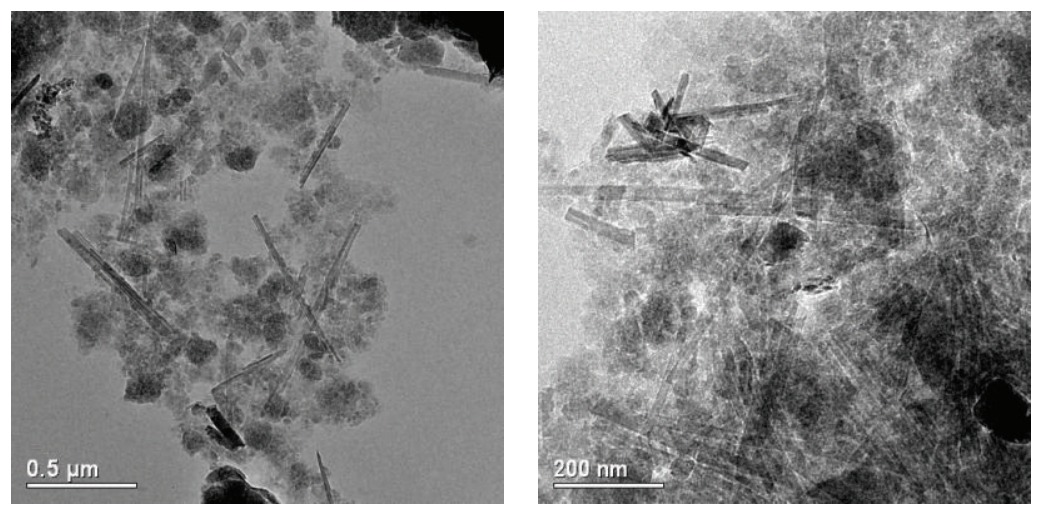

(a)
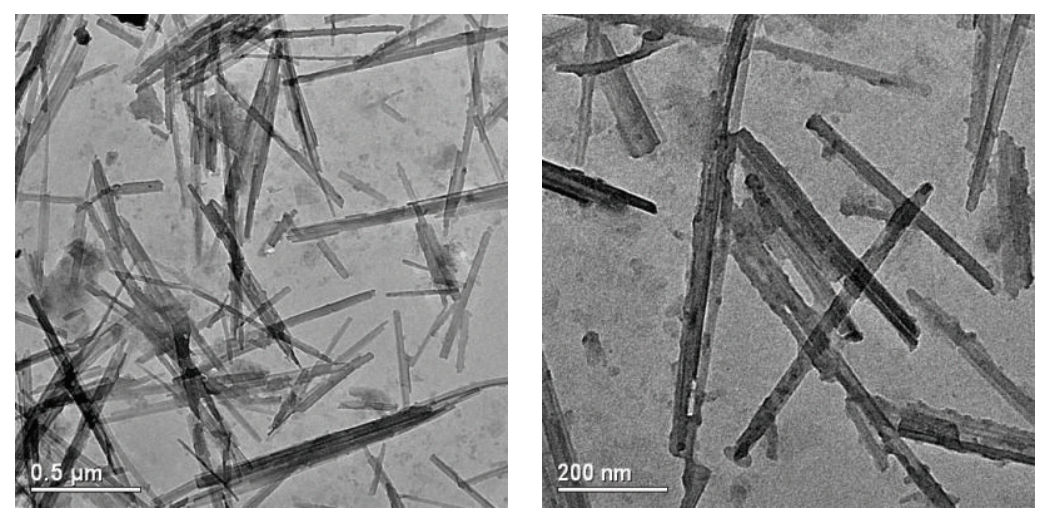

(b)
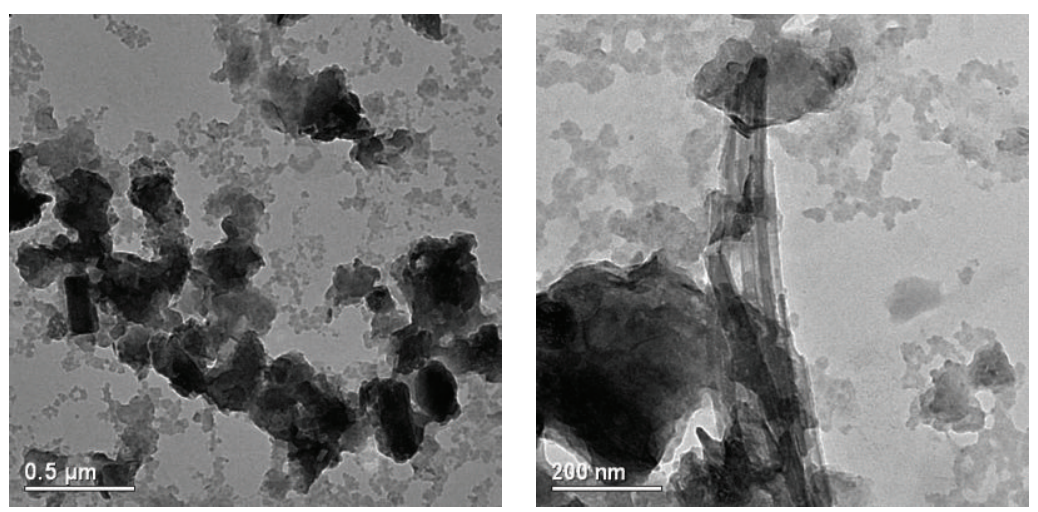

(c)
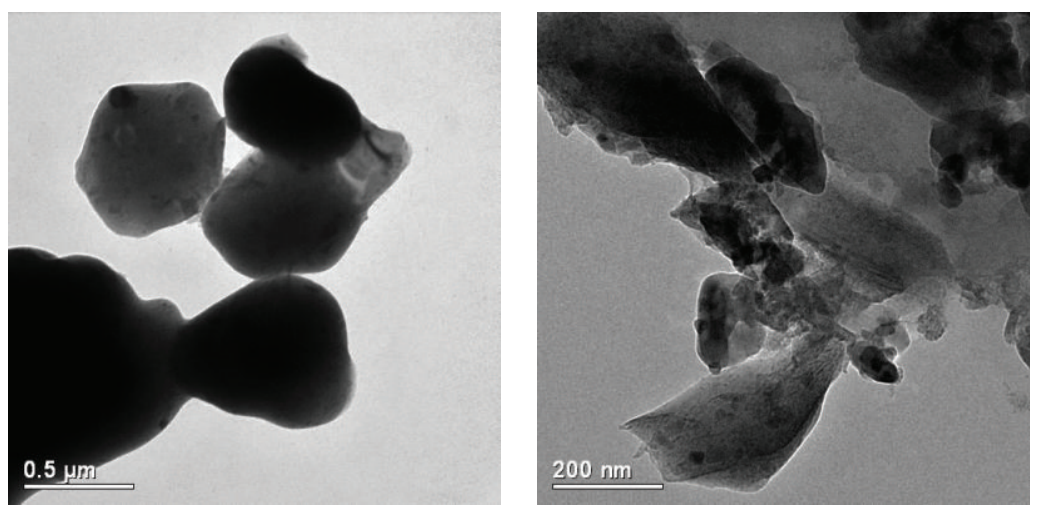

(d)

FIgUre 2: Transmission electron microscopy (TEM) images of (a) AT, (b) PAT, (c) PAT-450, and (d) PAT-850. 
that included fibrous and agglomerated $\mathrm{Mg}_{8} \mathrm{Si}_{12} \mathrm{O}_{30}(\mathrm{OH})_{4}$ particles from TEM (Figure 2(c)) when the treatment temperature was set at $450^{\circ} \mathrm{C}$. The structures of some AT particles changed from fibrous to agglomerated $\mathrm{Mg}_{8} \mathrm{Si}_{12} \mathrm{O}_{30}(\mathrm{OH})_{4}$ particles because of AT decomposition which caused some holes to disappear and destroyed a part of the microstructure of AT [36]. When the temperature reached $850^{\circ} \mathrm{C}$, the fibrous structure was not found, and the amount of agglomerated particles gradually increased (Figure 2(d)). The heat-treated attapulgite powders decomposed into silica and magnesium silicate at $850^{\circ} \mathrm{C}[31,35]$. The results showed that the sintering phenomenon was formed entirely by heating for $2 \mathrm{~h}$ at $850^{\circ} \mathrm{C}$ [36].

3.3. X-Ray Diffraction (XRD). The XRD patterns of AT, PAT, PAT-450, and PAT- 850 are shown in Figure 3. The peaks at $2 \theta=8.5^{\circ}, 13.93^{\circ}, 19.70^{\circ}$, and $26.5^{\circ}$ correspond to the primary diffraction of the (110), (200), (040), and (400) planes of AT, respectively $[35,41]$. Meanwhile, the characteristic peaks of the four planes of AT and PAT showed no change. Melo et al. [42] reported that treatment at $450^{\circ} \mathrm{C}$ had little effect on the crystal structure of AT. However, there were two morphologies of PAT- 450 that included fibrous and agglomerated $\mathrm{Mg}_{8} \mathrm{Si}_{12} \mathrm{O}_{30}(\mathrm{OH})_{4}$ particles. The intensity of peak at $2 \theta=$ $8.5^{\circ}$ was weaker compared with PAT and PAT-450 which due to some holes in PAT-450 disappeared. But the other characteristic peaks of PAT-450 were not obviously changed. This phenomenon might be the characteristic diffraction peaks between $\mathrm{Mg}_{8} \mathrm{Si}_{12} \mathrm{O}_{30}(\mathrm{OH})_{4}$ and attapulgite that were overlapped. The crystal structure of AT was destroyed at $850^{\circ} \mathrm{C}$. The characteristic diffraction peaks of attapulgite at $8.5^{\circ}$ and $19.7^{\circ}$ disappeared, indicating the change in the crystal structure of AT as well as the disappearance of its interlayer space [38]. The reflection at $2 \theta=26.7^{\circ}$ was due to the formation of amorphous silica [29]. This result is consistent with the TEM image of PAT-850.

3.4. BET Specific Surface Areas. The specific surface areas (calculated using the BET equation) of the different AT samples are shown in Table 3. Before and after the purification treatment, the surface areas of the AT were 143 and $126 \mathrm{~m}^{2} / \mathrm{g}$, respectively. The surface area of PAT was reduced compared with the original AT. Some impurities in AT may have adsorbed nitrogen. After purification, they were removed from AT, which resulted in the significant decrease in the surface area of PAT. Specific surface area of AT decreased as the temperature increased. When the temperature was set at $450^{\circ} \mathrm{C}$, the surface area of PAT450 further decreased to $80 \mathrm{~m}^{2} / \mathrm{g}$. The reason for such manifestation is that some AT particles changed from fibrous to agglomerated $\mathrm{Mg}_{8} \mathrm{Si}_{12} \mathrm{O}_{30}(\mathrm{OH})_{4}$ particles produced from AT decomposed, which caused some holes to disappear and destroy the microstructure of AT. As a result, the specific surface areas were reduced.

The surface area of PAT- 850 rapidly decreased to $0.6 \mathrm{~m}^{2} / \mathrm{g}$ at $850^{\circ} \mathrm{C}$. This decrease can be explained in two ways. One is that the PAT-850 structure was entirely destroyed and the holes completely disappeared. At higher temperatures,

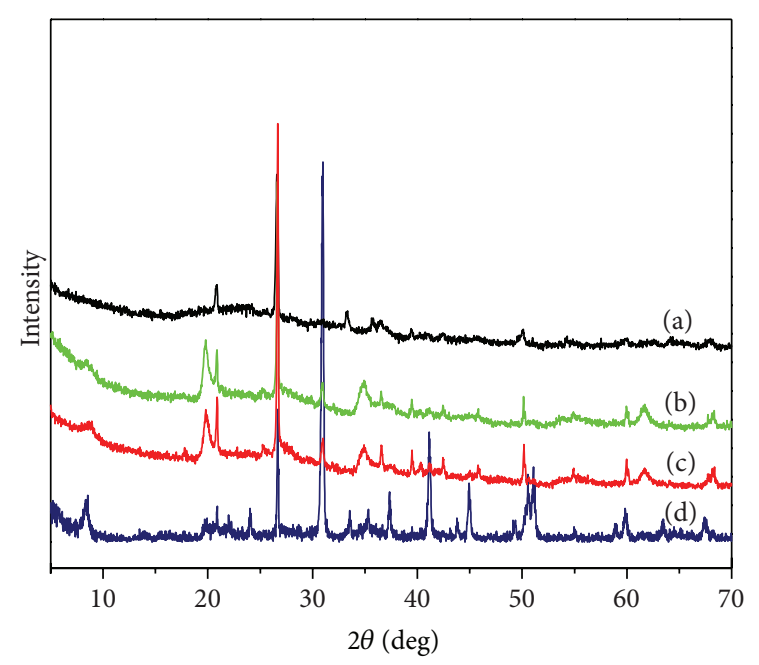

FIgUre 3: X-ray diffraction (XRD) patterns of (a) PAT-850, (b) PAT450, (c) PAT, and (d) AT.

TABLE 3: Specific surface areas of AT, PAT, PAT-450, and PAT-850.

\begin{tabular}{lcccc}
\hline Sample & AT & PAT & PAT-450 & PAT-850 \\
\hline Specific surface area $\left(\mathrm{m}^{2} / \mathrm{g}\right)$ & 143 & 126 & 80 & 0.6 \\
\hline
\end{tabular}

fibers became shrunker and curled, intra- and interparticles sintered, and the structure folded and pores were blocked resulting from decomposing and collapsing of the layers of the attapulgite [33]. Another factor was that the aggregation of the PAT-850 particles dramatically increased.

\subsection{Rheometric Characteristics of NR/PAT Nanocomposites.} The rheometric characteristics of the different NR nanocomposites are shown in Table 4, where $M_{L}, M_{H}, t s_{2}$, and $t_{90}$ were minimum torque, maximum torque, scorch time, and optimum cure time, respectively. The results showed that each nanocomposite exhibited different cure characteristics due to different properties of the fillers. The $\Delta M$ was the rough measurement of the cross-linking degree of rubber during vulcanization which could be used as an indirect indication of the cross-link density of the rubber compound $[43,44]$. Nanocomposites loading different AT caused a significant decrease in $t_{90}$ and $t s_{2}$ and increased in $M_{L}$ and $M_{H}$ compared with pristine natural rubber. It was revealed that AT increase curing process of natural rubber.

Table 4 indicated that the values of $M_{L}, M_{H}$, and $\Delta M$ increase continuously with PAT content increase. The increment in the torque with PAT content was due to the presence of more fibres structure which imparted more restriction to the deformation and consequently increased the NR/PAT composites stiffness. The larger the surface area is, the greater the interaction between the filler and rubber matrix is [45]. The structure of the PAT- 450 particles contains fibers and $\mathrm{Mg}_{8} \mathrm{Si}_{12} \mathrm{O}_{30}(\mathrm{OH})_{4}$ particles, which promoted particle dispersion in rubber. This dispersal showed that the interfacial interaction between PAT- 450 and the NR matrix as well as the cross-linking density of the composite increased. The 
TABLE 4: Curing properties of the NR/PAT nanocomposites.

\begin{tabular}{lccccc}
\hline Sample & $t \mathrm{~s}_{2}(\mathrm{~s})$ & $t_{90}(\mathrm{~s})$ & $M_{L}(\mathrm{~N} \cdot \mathrm{m})$ & $M_{H}(\mathrm{~N} \cdot \mathrm{m})$ & $\Delta M_{H}-M_{H}-M_{L}(\mathrm{~N} \cdot \mathrm{m})$ \\
\hline NR & $91 \pm 3$ & $207 \pm 5$ & $0.01 \pm 0.00$ & $0.53 \pm 0.02$ & $0.52 \pm 0.02$ \\
NR/PAT-0.5\% & $46 \pm 2$ & $76 \pm 3$ & $0.02 \pm 0.01$ & $0.56 \pm 0.03$ & $0.54 \pm 0.04$ \\
NR/PAT-1\% & $56 \pm 3$ & $105 \pm 3$ & $0.03 \pm 0.01$ & $0.61 \pm 0.02$ & $0.57 \pm 0.03$ \\
NR/PAT-3\% & $58 \pm 2$ & $113 \pm 2$ & $0.03 \pm 0.01$ & $0.63 \pm 0.03$ & $0.60 \pm 0.04$ \\
NR/PAT-5\% & $69 \pm 3$ & $115 \pm 2$ & $0.03 \pm 0.01$ & $0.64 \pm 0.03$ & $0.61 \pm 0.04$ \\
NR/PAT-10\% & $75 \pm 4$ & $116 \pm 4$ & $0.04 \pm 0.01$ & $0.75 \pm 0.02$ & $0.71 \pm 0.03$ \\
NR/PAT-450-0.5\% & $43 \pm 2$ & $72 \pm 4$ & $0.02 \pm 0.01$ & $0.58 \pm 0.03$ & $0.56 \pm 0.04$ \\
NR/PAT-450-1\% & $51 \pm 3$ & $74 \pm 3$ & $0.03 \pm 0.01$ & $0.62 \pm 0.02$ & $0.60 \pm 0.03$ \\
NR/PAT-450-3\% & $52 \pm 3$ & $74 \pm 2$ & $0.03 \pm 0.01$ & $0.63 \pm 0.03$ & $0.60 \pm 0.04$ \\
NR/PAT-450-5\% & $56 \pm 2$ & $105 \pm 4$ & $0.03 \pm 0.01$ & $0.69 \pm 0.02$ & $0.66 \pm 0.03$ \\
NR/PAT-450-10\% & $56 \pm 3$ & $106 \pm 3$ & $0.04 \pm 0.01$ & $0.74 \pm 0.02$ & $0.02 \pm 0.03$ \\
NR/PAT-850-0.5\% & $45 \pm 2$ & $68 \pm 3$ & $0.02 \pm 0.01$ & $0.64 \pm 0.03$ & $0.62 \pm 0.04$ \\
NR/PAT-850-1\% & $46 \pm 3$ & $69 \pm 2$ & $0.03 \pm 0.01$ & $0.65 \pm 0.02$ & $0.62 \pm 0.03$ \\
NR/PAT-850-3\% & $50 \pm 3$ & $69 \pm 4$ & $0.03 \pm 0.01$ & $0.67 \pm 0.03$ & $0.64 \pm 0.04$ \\
NR/PAT-850-5\% & $52 \pm 2$ & $75 \pm 3$ & $0.03 \pm 0.01$ & $0.70 \pm 0.02$ & $0.67 \pm 0.03$ \\
NR/AT-850-10\% & $54 \pm 3$ & $111 \pm 5$ & $0.04 \pm 0.01$ & $0.73 \pm 0.02$ & $0.69 \pm 0.03$ \\
\hline
\end{tabular}

TABLE 5: Mechanical properties of the NR/PAT nanocomposites.

\begin{tabular}{lccccc}
\hline Sample & $\begin{array}{c}\text { Stress at 300\% } \\
(\mathrm{MPa})\end{array}$ & $\begin{array}{c}\text { Elongation at break } \\
(\%)\end{array}$ & $\begin{array}{c}\text { Tensile strength } \\
(\mathrm{MPa})\end{array}$ & $\begin{array}{c}\text { Shore hardness } \\
(\mathrm{SHA})\end{array}$ & $\begin{array}{c}\text { Abrasion volume } \\
\left(\mathrm{cm}^{3}\right)\end{array}$ \\
\hline NR & $1.60 \pm 0.04$ & $592 \pm 18$ & $15.45 \pm 0.51$ & $46 \pm 1$ & $1.155 \pm 0.013$ \\
NR/PAT-0.5\% & $1.64 \pm 0.05$ & $415 \pm 15$ & $19.34 \pm 0.56$ & $46 \pm 1$ & $0.723 \pm 0.015$ \\
NR/PAT-1\% & $2.07 \pm 0.07$ & $432 \pm 15$ & $23.27 \pm 0.45$ & $50 \pm 2$ & $0.659 \pm 0.014$ \\
NR/PAT-3\% & $1.59 \pm 0.07$ & $431 \pm 16$ & $21.23 \pm 0.52$ & $47 \pm 1$ & $0.765 \pm 0.015$ \\
NR/PAT-5\% & $1.68 \pm 0.05$ & $427 \pm 17$ & $20.40 \pm 0.63$ & $50 \pm 1$ & $0.812 \pm 0.016$ \\
NR/PAT-10\% & $1.39 \pm 0.06$ & $425 \pm 14$ & $16.69 \pm 0.46$ & $46 \pm 2$ & $1.061 \pm 0.017$ \\
NR/PAT-450-0.5\% & $2.44 \pm 0.07$ & $397 \pm 16$ & $24.45 \pm 0.45$ & $52 \pm 2$ & $0.235 \pm 0.012$ \\
NR/PAT-450-1\% & $2.53 \pm 0.08$ & $418 \pm 14$ & $29.69 \pm 0.41$ & $54 \pm 1$ & $0.043 \pm 0.009$ \\
NR/PAT-450-3\% & $2.84 \pm 0.07$ & $397 \pm 18$ & $26.60 \pm 0.33$ & $54 \pm 1$ & $0.333 \pm 0.012$ \\
NR/PAT-450-5\% & $3.86 \pm 0.08$ & $356 \pm 14$ & $25.03 \pm 0.57$ & $58 \pm 2$ & $0.336 \pm 0.011$ \\
NR/PAT-450-10\% & $3.15 \pm 0.08$ & $354 \pm 17$ & $23.27 \pm 0.64$ & $54 \pm 2$ & $0.340 \pm 0.012$ \\
NR/PAT-850-0.5\% & $1.85 \pm 0.05$ & $466 \pm 18$ & $23.45 \pm 0.53$ & $50 \pm 1$ & $0.324 \pm 0.013$ \\
NR/PAT-850-1\% & $2.03 \pm 0.05$ & $481 \pm 13$ & $28.63 \pm 0.47$ & $51 \pm 2$ & $0.135 \pm 0.012$ \\
NR/PAT-850-3\% & $1.96 \pm 0.05$ & $452 \pm 17$ & $25.21 \pm 0.66$ & $51 \pm 1$ & $0.429 \pm 0.014$ \\
NR/PAT-850-5\% & $2.20 \pm 0.07$ & $434 \pm 18$ & $24.04 \pm 0.35$ & $19.93 \pm 0.57$ & $52 \pm 2$ \\
NR/PAT-850-10\% & $1.33 \pm 0.07$ & $412 \pm 15$ & & $47 \pm 1$ & $0.438 \pm 0.013$ \\
\hline
\end{tabular}

larger $\Delta M$ of NR/PAT-850 showed the stronger interactions between $\mathrm{SiO}_{2}$ particles and natural rubber which were abundant $-\mathrm{OH}$ groups on the surface of the $\mathrm{SiO}_{2}$.

It could be found that the scorch time and optimum cure time of nanocomposites increased with increasing filler loading. At a similar filler loading, PAT exhibited longer $t \mathrm{~s}_{2}$ and $t_{90}$ than PAT-450 and PAT-850. One reason was that the high specific surface areas and the charges on the lattice allowed the AT to adsorb the vulcanizing and curing agents easily. The adsorption increased as the AT content varied from $0.5 \%$ to $10 \%$. Accordingly, contrary to the reduction of accelerator concentration which may be imagined to result in longer scorch time. The other reason was that AT contained a large number of bound water and hydroxyl groups on the surface of attapulgite; they could adsorb the curatives and also caused delay of the $t \mathrm{~s}_{2}$ and $t_{90}$ of rubber compound. The scorch time and optimum cure time of NR/PAT-850 were increased possibly due to amorphous silica containing hydroxyl groups $(-\mathrm{OH})$ [46] which absorbs the curative agents and thus reduce the active sulphurating agent.

3.6. Mechanical Properties of the NR/PAT Nanocomposites. The mechanical properties of the AT-filled systems are shown in Table 5. Mechanical properties of NR/PAT nanocomposites like tensile strength and elongation at break increased 
with the increase in filler loading up to $1 \mathrm{phr}$, thereafter these properties marginally fall when loading is increased to $10 \mathrm{phr}$. However, the abrasion volume showed an opposite tendency to that of the nanocomposite tensile properties. Lower amounts of AT can easily disperse in the nanocomposites. This may be attributed to a significant improvement in the filler matrix-interfacial bonding, better dispersion of the filler in the blend, which leads to an increased in the efficiency of stress transfer from the matrix to the filler phases. With increasing AT concentration, the tensile properties decreased. This means that addition of more AT concentration seems to cause agglomeration and interruption filler-matrix bonding. The optimum loading of AT appears to be one per one hundred rubber. The results also show that thermally-treated AT exhibited an improved dispersion and enhanced the chemical interfacial adhesion with the matrix, which exhibited "nanometer effect" and "physical cross-link" of attapulgite [47].

NR/PAT-450 had a positive effect on the nanocomposite tensile properties, which reached $29.69 \mathrm{MPa}$ when $1 \mathrm{wt} \%$ filler was added to NR. This result indicates a 100\% improvement compared with pure NR. It also can be found that PAT-850 had a good reinforce filler for natural rubber. Such improvement is attributed to PAT decomposing into amorphous silica at $850^{\circ} \mathrm{C}$. Silica is one of the reinforcing fillers widely used in rubber compounds $[48,49]$.

3.7. Swelling Ratio of NR/PAT Nanocomposites. The swelling ratio of the NR/PAT nanocomposites in toluene was investigated; the results are shown in Figure 4. The first section of the swelling ratio curves revealed the high swelling rate because of the large concentration gradients, and the samples are under severe solvent stress, whereas the second section indicated a reduced swelling rate due to a decrease in concentration gradient, and the swelling process almost reached equilibrium.

The swelling test results indicate some type of relationship with the tensile properties of the NR composites. The NR/PAT nanocomposites exhibited significantly lower swelling ratios compared with NR in the absence of filler. In particular, the nanocomposite with PAT-450 content of $1 \mathrm{wt} \%$ exhibited the lowest swelling ratio, which indicated that penetration of toluene solvent into rubber compound was restricted. The nanocomposites filled with PAT, PAT-450, and PAT- 850 reached the swelling equilibrium after $24 \mathrm{~h}$, whereas the NR required $50 \mathrm{~h}$ to reach the same state. As a result, PAT could provide a barrier system against toluene solvent. This may be attributed to the uniform dispersion of PAT particles in natural rubber matrix, thus contributing to better rubberfiller interaction $[50,51]$.

3.8. SEM Analysis. The morphologies of the fracture surface of the NR/PAT nanocomposites were examined by SEM. Figure 5(a) showed the SEM micrograph of pristine NR. The fractured section of pristine NR was smooth, while those of NR/PAT nanocomposites showed many irregularities (Figures 5(b), 5(c), and 5(d)). The morphology of the fracture surface of NR/PAT-1\% nanocomposite was showed

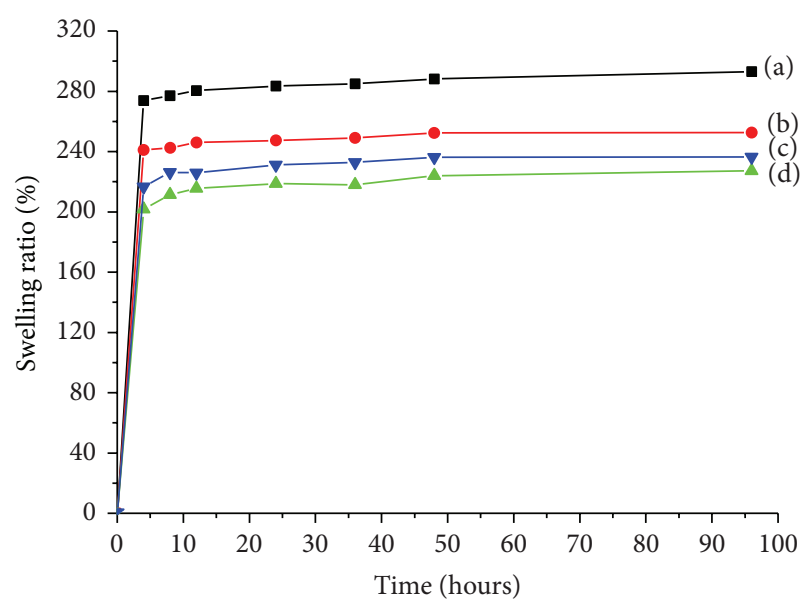

FIGURE 4: Swelling of various nanocomposites with the variations in the modified AT (a) NR, (b) NR/PAT-1\%, (c) NR/PAT-450-1\%, and (d) NR/PAT-850-1\%.

in Figure 5(b). The NR matrix was in gray, the attapulgite was in white, and the attapulgite fibers were dispersed uniformly in NR. The nanocomposite exhibited fibrous morphology, and a great deal of attapulgite fibers congregate into bundles. Most PAT fibrils were fractured and only a few fibrils were pulled out from the NR matrix [21]. This implies that the adhesion between PAT and the NR matrix is good [47].

The morphology of the fracture surface of NR/PAT450-1\% and NR/PAT-850-1\% nanocomposite was showed in Figures 5(c) and 5(d), respectively. When Figures 5(b), 5(c), and $5(\mathrm{~d})$ were compared, the results demonstrated that the fracture surface of NR/PAT450-1\% was the roughest with deeper tearing lines and angular cracking. In addition, the interface between PAT- 450 and the natural rubber matrix was not so clear. Similarly, the fracture surface of NR/PAT450-1\% nanocomposite was a few smaller holes, which indicated that the interfacial adhesion was still strong. Higher crack propagation energy was required to fracture this nanocomposite.

It also could be clearly seen that there were some big microcracks in the fracture surface of NR/PAT-850-1\%, which is due to PAT decomposing into amorphous silica at $850^{\circ} \mathrm{C}$. The interfacial bonding between silica and the rubber matrix was strong, thus resulting in higher values of tensile properties [52].

3.9. Thermogravimetric Analysis of the NR/PAT Nanocomposites. The thermal behavior of the nanocomposites was investigated using TG; the results are shown in Figure 6. The temperatures of $T_{5 \%}$ and $T_{\max }$ values of nanocomposites were listed in Table 6 . These TG curves indicated single-stage degradation with well defined initial and final degradation temperatures and might have been a result of a random chain scission process [53]. The nanocomposites filled with PAT, PAT-450, and PAT-850 displayed better thermal resistance than that of the pristine NR. $T_{5 \%}$ and $T_{\max }$ values for NR, NR/PAT-1\%, NR/PAT-450-1\%, and NR/PAT-850-1\% were found to occur at $215,285,309$, and $338^{\circ} \mathrm{C}$ and 374 , 393,391 , and $395^{\circ} \mathrm{C}$, respectively. Table 6 showed a $70-113^{\circ} \mathrm{C}$ 

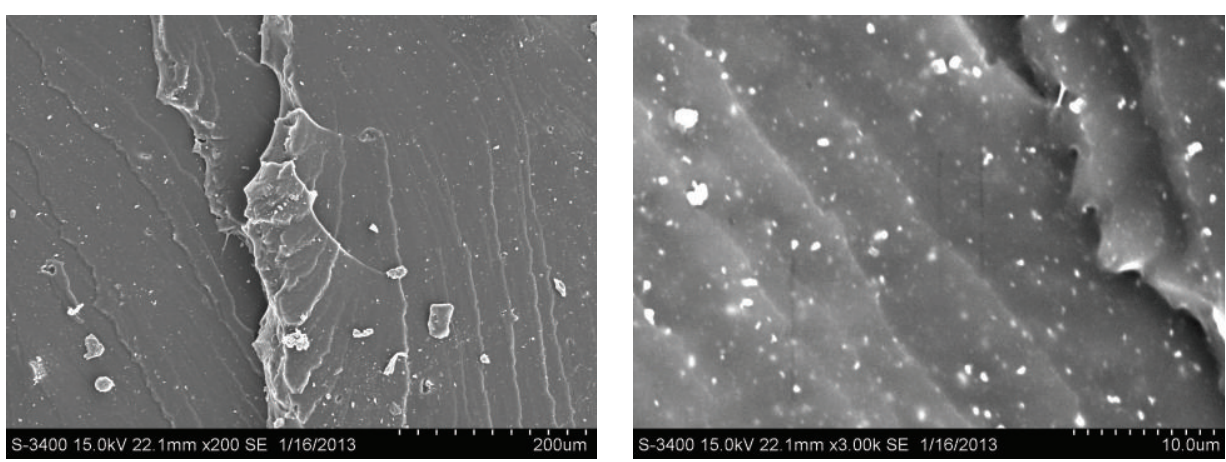

(a)
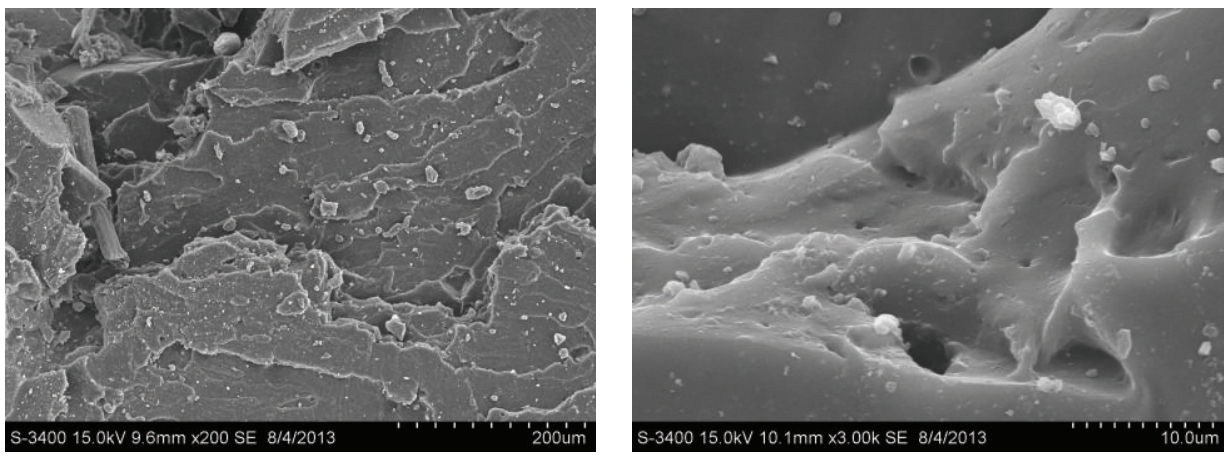

(b)
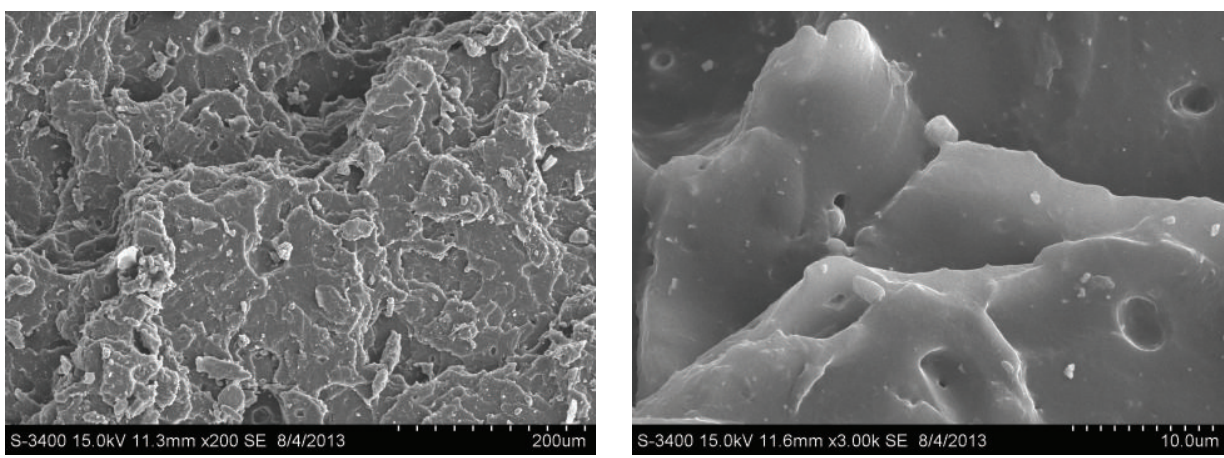

(c)
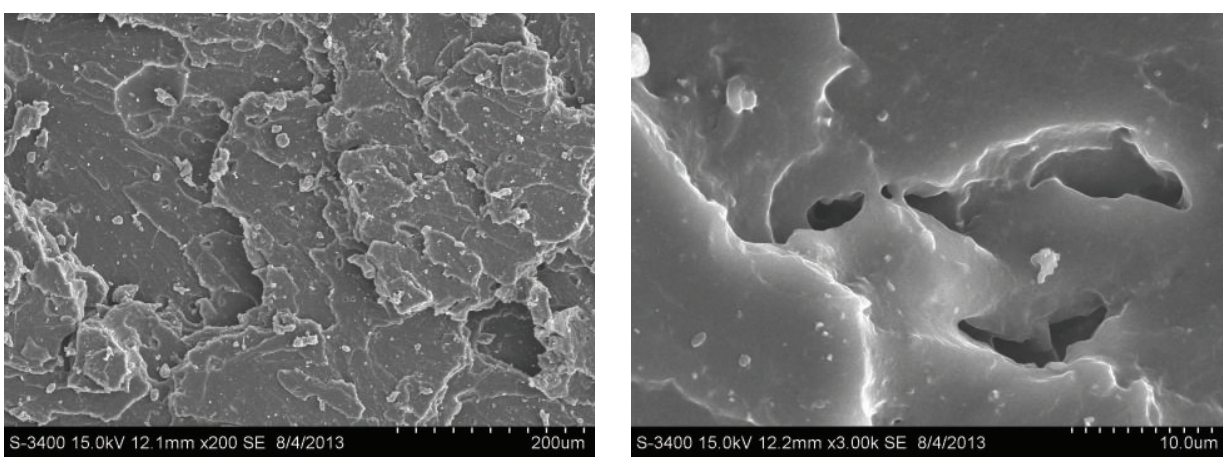

(d)

FIGURE 5: Fractographs of various nanocomposites with the variations in the modified AT (a) NR, (b) NR/PAT-1\%, (c) NR/PAT-450-1\%, and (d) NR/PAT-850-1\%. 


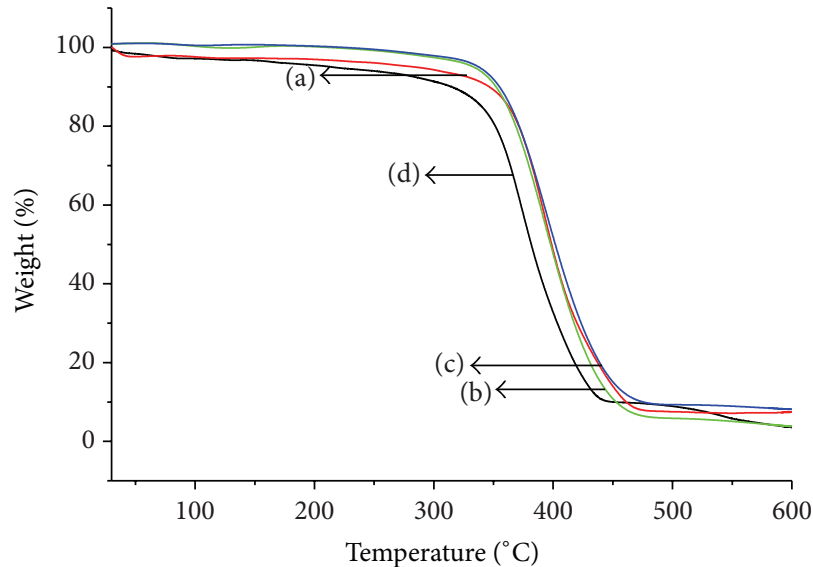

(a)

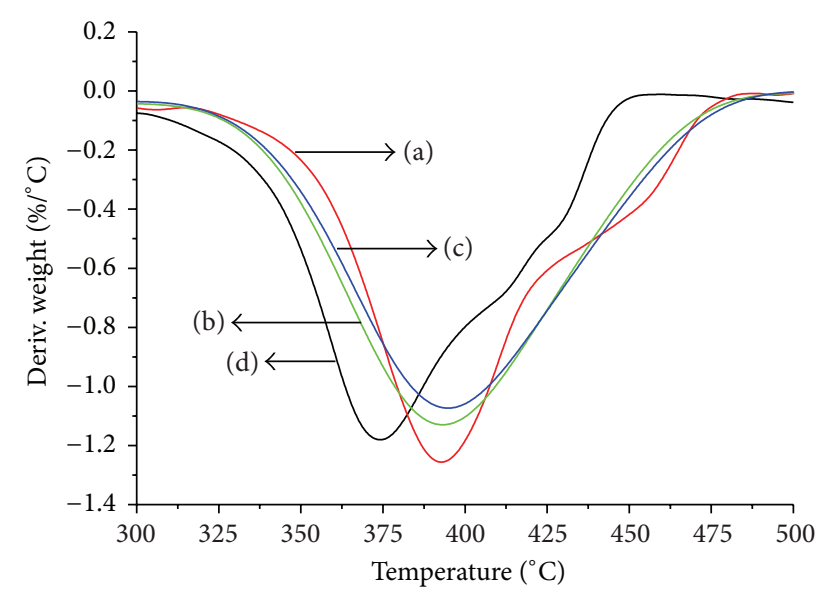

(b)

FIGURE 6: Thermograms of NR and NR/AT nanocomposites: (a) NR/PAT-1\%, (b) NR/PAT-450-1\%, (c) NR/PAT-850-1\%, and (d) NR.

TABLE 6: Thermal degradation of the NR/PAT nanocomposites.

\begin{tabular}{lccc}
\hline Sample & $\begin{array}{c}\text { Initial } \\
\text { degradation } \\
\text { temperature } \\
\left({ }^{\circ} \mathrm{C}\right) T_{5 \%}\end{array}$ & $\begin{array}{c}\text { Degradation } \\
\text { temperature } \\
\left({ }^{\circ} \mathrm{C}\right) T_{\max }\end{array}$ & $\begin{array}{c}\text { Residue mass } \\
\text { at } 600^{\circ} \mathrm{C}(\%)\end{array}$ \\
\hline NR & 215 & 374 & 3.58 \\
NR/PAT-1\% & 285 & 393 & 7.43 \\
NR/PAT-450-1\% & 309 & 391 & 7.57 \\
NR/PAT-850-1\% & 338 & 395 & 8.13 \\
\hline
\end{tabular}

increase in the initial degradation temperature and a 17$21^{\circ} \mathrm{C}$ increase in the degradation temperature of nanocomposites filled with PAT, PAT-450, and PAT-850. Attapulgite particles retarded the motion of the polymer chains, acted as insulators, and massed transport barriers to volatile products produced during thermal degrading which could enhance the thermal stability of polymer $[47,54]$. Four different types of hydroxyl group are present in PAT. Meanwhile, zeolitic and coordinated water are found in PAT-450. As the temperature increased, the moisture was gradually volatized. The heat conduction coefficients of the nanocomposites increased, whereas the heat transfer speed decreased. At the same time, the heat of the nanocomposites dissipated during moisture evaporation. PAT-850 improved the molecular interaction between AT and rubber and contributed in preventing the thermal degradation of rubber.

\section{Conclusions}

Pristine attapulgite was purified and modified attapulgite, which was treated at $450^{\circ} \mathrm{C}$ and $850^{\circ} \mathrm{C}$ for two hours. The structures and morphology of heated attapulgite was changed. NR nanocomposites reinforced with different AT were prepared using a direct melt-compounding method. A comparative study was performed to evaluate the effects of rheometric characteristics and mechanical properties of the
NR/AT nanocomposites. The $t_{90}, t \mathrm{~s}_{2} M_{L}, M_{H}$, and $\Delta M$ of the nanocomposites increased with increasing AT content. The tensile strength, abrasion resistance, and solvent resistance properties of the nanocomposites were significantly improved by the addition of PAT, PAT-450, or PAT-850. SEM results show that the filler is located at the interface among the natural rubber. TGA results show that the significantly improved thermal stability of nanocomposites.

\section{Conflict of Interests}

The authors declare that there is no conflict of interests regarding the publication of this paper.

\section{Acknowledgments}

This work was financially supported by the Science and Technology Development Foundation of Shanghai University of Engineering Science (2011XY23), Shanghai Municipality Science and Technology Commission Foundation (11490501500), and Shanghai Municipal Education Commission Foundation (11XK18B and XKCZ1205).

\section{References}

[1] K. W. Stöckelhuber, A. Das, R. Jurk, and G. Heinrich, "Contribution of physico-chemical properties of interfaces on dispersibility, adhesion and flocculation of filler particles in rubber," Polymer, vol. 51, no. 9, pp. 1954-1963, 2010.

[2] Y. Merckel, J. Diani, M. Brieu, and J. Caillard, "Effects of the amount of fillers and of the crosslink density on the mechanical behavior of carbon-black filled styrene butadiene rubbers," Journal of Applied Polymer Science, vol. 129, no. 4, pp. 20862091, 2013.

[3] H. Nabil, H. Ismail, and A. R. Azura, "Compounding, mechanical and morphological properties of carbon-black-filled natural rubber/recycled ethylene-propylene-diene-monomer (NR/REPDM) blends," Polymer Testing, vol. 32, no. 2, pp. 385-393, 2013. 
[4] S. Agnelli, G. Ramorino, S. Passera, J. Karger-Kocsis, and T. Ricco, "Fracture resistance of rubbers with MWCNT, organoclay, silica and carbon black fillers as assessed by the J-integral: effects of rubber type and filler concentration," Express Polymer Letters, vol. 6, no. 7, pp. 581-587, 2012.

[5] Z. Peng, L. X. Kong, S.-D. Li, Y. Chen, and M. F. Huang, "Selfassembled natural rubber/silica nanocomposites: its preparation and characterization," Composites Science and Technology, vol. 67, no. 15-16, pp. 3130-3139, 2007.

[6] C. A. Rezende, F. C. Bragança, T. R. Doi, L.-T. Lee, F. Galembeck, and F. Boué, "Natural rubber-clay nanocomposites: mechanical and structural properties," Polymer, vol. 51, no. 16, pp. 36443652, 2010.

[7] M. N. Qureshi and H. Qammar, "Mill processing and properties of rubber-clay nanocomposites," Materials Science and Engineering C, vol. 30, no. 4, pp. 590-596, 2010.

[8] A. Lagazzo, S. Lenzi, R. Botter, P. Cirillo, F. Demicheli, and D. T. Beruto, "A rheological method for selecting nano-kaolin powder as filler in SBR rubber," Particuology, vol. 8, no. 3, pp. 245-250, 2010.

[9] Y. Zhang, Q. Liu, Q. Zhang, and Y. Lu, "Gas barrier properties of natural rubber/kaolin composites prepared by melt blending," Applied Clay Science, vol. 50, no. 2, pp. 255-259, 2010.

[10] S. L'alíková, M. Pajtášová, M. Chromčíková et al., "Investigation of natural rubber composites with addition of montmorillonite fillers using thermal analysis," Journal of Thermal Analysis and Calorimetry, vol. 104, no. 3, pp. 969-973, 2011.

[11] Z. M. Jia, S. J. Chen, and J. Zhang, "RTV silicone rubber filled with surface modified montmorillonite," Journal of Macromolecular Science B, no. 51, pp. 2449-2461, 2012.

[12] Q. Fu, L. Chen, K. Liu, F. Chen, and T. X. Jin, "Rod like attapulgite/poly(ethylene terephthalate) nanocomposites with chemical bonding between the polymer chain and the filler," EXPRESS Polymer Letters, vol. 6, no. 8, pp. 629-638, 2012.

[13] N. A. Azahari, N. Othman, and H. Ismail, "Effect of attapulgite clay on biodegradability and tensile properties of polyvinyl alcohol/corn starch blend film international," Journal of Polymeric Materials, no. 61, pp. 1065-1078, 2012.

[14] J. Shi, X. Yang, Q. Han, X. Wang, and L. Lu, "Polyurethane grafted attapulgite as novel fillers for nylon 6 nanocomposites," Journal Wuhan University of Technology, Materials Science Edition, vol. 26, no. 4, pp. 615-619, 2011.

[15] R. M. B. Fernandes, L. L. Y. Visconte, and R. C. R. Nunes, "Characteristics of acrylic rubber composites with mica and carbon black," Journal of Elastomers and Plastics, vol. 42, no. 1 , pp. 65-74, 2010.

[16] W. F. Bradley, “The structural scheme of attapulgite," American Mineralogist, vol. 25, no. 6, pp. 405-410, 1940.

[17] P. Liu and T. Wang, "Adsorption properties of hyperbranched aliphatic polyester grafted attapulgite towards heavy metal ions," Journal of Hazardous Materials, vol. 149, no. 1, pp. 75-79, 2007.

[18] J. Zhang, Q. Wang, and A. Wang, "Synthesis and characterization of chitosan-g-poly(acrylic acid)/attapulgite superabsorbent composites," Carbohydrate Polymers, vol. 68, no. 2, pp. 367-374, 2007.

[19] C. H. Chen, "Effect of attapulgite on the crystallization behavior and mechanical properties of poly(butylene succinate) nanocomposites," Journal of Physics and Chemistry of Solids, vol. 69, no. 5-6, pp. 1411-1414, 2008.
[20] Y. Chen, Y. Zhao, S. Zhou, X. Chu, L. Yang, and W. Xing, "Preparation and characterization of polyacrylamide/palygorskite," Applied Clay Science, vol. 46, no. 2, pp. 148-152, 2009.

[21] M. Tian, W. Liang, G. Rao, L. Zhang, and C. Guo, "Surface modification of fibrillar silicate and its reinforcing mechanism on FS/rubber composites," Composites Science and Technology, vol. 65, no. 7-8, pp. 1129-1138, 2005.

[22] J. Huang, Y. Liu, and X. Wang, "Influence of differently modified palygorskites in the immobilization of a lipase," Journal of Molecular Catalysis B, vol. 55, no. 1-2, pp. 49-54, 2008.

[23] J. Zhang, H. Chen, and A. Wang, "Study on superabsorbent composite. III. Swelling behaviors of polyacrylamide/ attapulgite composite based on acidified attapulgite and organoattapulgite," European Polymer Journal, vol. 41, no. 10, pp. 24342442, 2005.

[24] Y. I. Jin, J. Chen, and Y. H. Qian, "The methodology and mechanism analysis of stearic acid-modified attapulgite reinforcing polyurethane leather," Journal of Wuhan University of Technology, vol. 27, no. 12, pp. 9-13, 2005.

[25] Y. Xiang, Z. Peng, and D. Chen, "A new polymer/clay nanocomposite hydrogel with improved response rate and tensile mechanical properties," European Polymer Journal, vol. 42, no. 9, pp. 2125-2132, 2006.

[26] Y. Liu, P. Liu, Z. Su, F. Li, and F. Wen, "Attapulgite- $\mathrm{Fe}_{3} \mathrm{O}_{4}$ magnetic nanoparticles via co-precipitation technique," Applied Surface Science, vol. 255, no. 5, pp. 2020-2025, 2008.

[27] Y. Liu, P. Liu, and Z. Su, "Core-shell attapulgite@polyaniline composite particles via in situ oxidative polymerization," Synthetic Metals, vol. 157, no. 13-15, pp. 585-591, 2007.

[28] S. Q. Lai, T. S. Li, X. J. Liu, R. G. Lv, and L. Yue, "The tribological properties of PTFE filled with thermally treated nano-attapulgite," Tribology International, vol. 39, no. 6, pp. 541$547,2006$.

[29] S. Lai, L. Yue, X. Zhao, and L. Gao, "Preparation of silica powder with high whiteness from palygorskite," Applied Clay Science, vol. 50, no. 3, pp. 432-437, 2010.

[30] F. Gan, J. Zhou, H. Wang, C. Du, and X. Chen, "Removal of phosphate from aqueous solution by thermally treated natural palygorskite," Water Research, vol. 43, no. 11, pp. 2907-2915, 2009.

[31] V. Vágvölgyi, L. M. Daniel, C. Pinto, J. Kristóf, R. L. Frost, and E. Horváth, "Dynamic and controlled rate thermal analysis of attapulgite," Journal of Thermal Analysis and Calorimetry, vol. 92, no. 2, pp. 589-594, 2008.

[32] S. Lokanatha, B. K. Mathur, B. K. Samantaray, and S. Bhattacherjee, "Dehydration and phase transformation in attapulgite (palygorskite) - an R.D.F. study," Journal of Materials Science Letters, vol. 3, no. 12, pp. 1105-1108, 1984.

[33] R. L. Frost, G. A. Cash, and J. T. Kloprogge, “'Rocky Mountain leather', sepiolite and attapulgite- an infrared emission spectroscopic study," Vibrational Spectroscopy, vol. 16, no. 2-3, pp. 173184, 1998.

[34] R. L. Frost, O. B. Locos, H. Ruan, and J. T. Kloprogge, "Nearinfrared and mid-infrared spectroscopic study of sepiolites and palygorskites," Vibrational Spectroscopy, vol. 27, no. 1, pp. 1-13, 2001.

[35] G. Tartaglione, D. Tabuani, and G. Camino, "Thermal and morphological characterisation of organically modified sepiolite," Microporous and Mesoporous Materials, vol. 107, no. 1-2, pp. 161$168,2008$. 
[36] T. Chen, J. Wang, C. Qing, S. Peng, Y. Song, and Y. Guo, "Effect of heat treatment on structure, morphology and surface properties of palygorskite," Journal of the Chinese Ceramic Society, vol. 34, no. 11, pp. 1406-1410, 2006.

[37] B. Xu, W. M. Huang, Y. T. Pei et al., "Mechanical properties of attapulgite clay reinforced polyurethane shape-memory nanocomposites," European Polymer Journal, vol. 45, no. 7, pp. 1904-1911, 2009.

[38] J. H. Huang, Y. F. Liu, Q. Z. Jin, and X. G. Wang, "Spectra study on the influence of drying process on palygorskite structure," Spectroscopy and Spectral Analysis, vol. 27, no. 2, pp. 408-410, 2007.

[39] J. Madejová, "FTIR techniques in clay mineral studies," Vibrational Spectroscopy, vol. 31, no. 1, pp. 1-10, 2003.

[40] R. L. Frost and Z. Ding, "Controlled rate thermal analysis and differential scanning calorimetry of sepiolites and palygorskites," Thermochimica Acta, vol. 397, no. 1-2, pp. 119-128, 2003.

[41] D. M. Araújo Melo, J. A. C. Ruiz, M. A. F. Melo, E. V. Sobrinho, and A. E. Martinelli, "Preparation and characterization of lanthanum palygorskite clays as acid catalysts," Journal of Alloys and Compounds, vol. 344, no. 1-2, pp. 352-355, 2002.

[42] D. M. A. Melo, J. A. C. Ruiz, M. A. F. Melo, E. V. Sobrinho, and M. Schmall, "Preparation and characterization of terbium palygorskite clay as acid catalyst," Microporous and Mesoporous Materials, vol. 38, no. 2-3, pp. 345-349, 2000.

[43] M. M. Saatchi and A. Shojaei, "Effect of carbon-based nanoparticles on the cure characteristics and network structure of styrene-butadiene rubber vulcanizate," Polymer International, vol. 61, no. 4, pp. 664-672, 2012.

[44] J. Vojislav, S. J. Suzana, B. S. Jaroslava, M. Gordana, and M. C. Milena, "Composites based on carbon black reinforced NBR/EPDM rubber blends," Composites Part B, vol. 45, no. 1, pp. 333-340, 2013.

[45] H. Ismail, H. D. Rozman, R. M. Jaffri, and Z. A. Mohd Ishak, "Oil palm wood flour reinforced epoxidized natural rubber composites: the effect of filler content and size," European Polymer Journal, vol. 33, no. 10-12, pp. 1627-1632, 1997.

[46] H. Ismail, H. Osman, and A. Ariffin, "A comparative study on curing characteristics, mechanical properties, swelling behavior, thermal stability, and morphology of feldspar and silica in SMR L vulcanizates," Polymer, vol. 43, no. 5, pp. 1323-1344, 2004.

[47] H. Chen, M. Zheng, H. Sun, and Q. Jia, "Characterization and properties of sepiolite/polyurethane nanocomposites," Materials Science and Engineering A, vol. 445-446, pp. 725-730, 2007.

[48] S. Prasertsri and N. Rattanasom, "Fumed and precipitated silica reinforced natural rubber composites prepared from latex system: mechanical and dynamic properties," Polymer Testing, vol. 31, no. 5, pp. 593-605, 2012.

[49] K. Sahakaro and S. Beraheng, "Reinforcement of maleated natural rubber by precipitated silica," Journal of Applied Polymer Science, vol. 109, no. 6, pp. 3839-3848, 2008.

[50] Z. X. Ooi, H. Ismail, and A. A. Bakar, "Synergistic effect of oil palm ash filled natural rubber compound at low filler loading," Polymer Testing, vol. 32, no. 1, pp. 38-44, 2013.

[51] T. Pojanavaraphan, D. A. Schiraldi, and R. Magaraphan, "Mechanical, rheological, and swelling behavior of natural rubber/montmorillonite aerogels prepared by freeze-drying," Applied Clay Science, vol. 50, no. 2, pp. 271-279, 2010.
[52] D. Fragiadakis, L. Bokobza, and P. Pissis, "Dynamics near the filler surface in natural rubber-silica nanocomposites," Polymer, vol. 52, no. 14, pp. 3175-3182, 2011.

[53] J. P. Rath, T. K. Chaki, and D. Khastgir, "Development of natural rubber-fibrous nano clay attapulgite composites: the effect of chemical treatment of filler on mechanical and dynamic mechanical properties of composites," Procedia Chemistry, vol. 4, pp. 131-137, 2012.

[54] N. Volle, F. Giulieri, A. Burr, S. Pagnotta, and A. M. Chaze, "Controlled interactions between silanol groups at the surface of sepiolite and an acrylate matrix: consequences on the thermal and mechanical properties," Materials Chemistry and Physics, vol. 134, no. 1, pp. 417-424, 2012. 

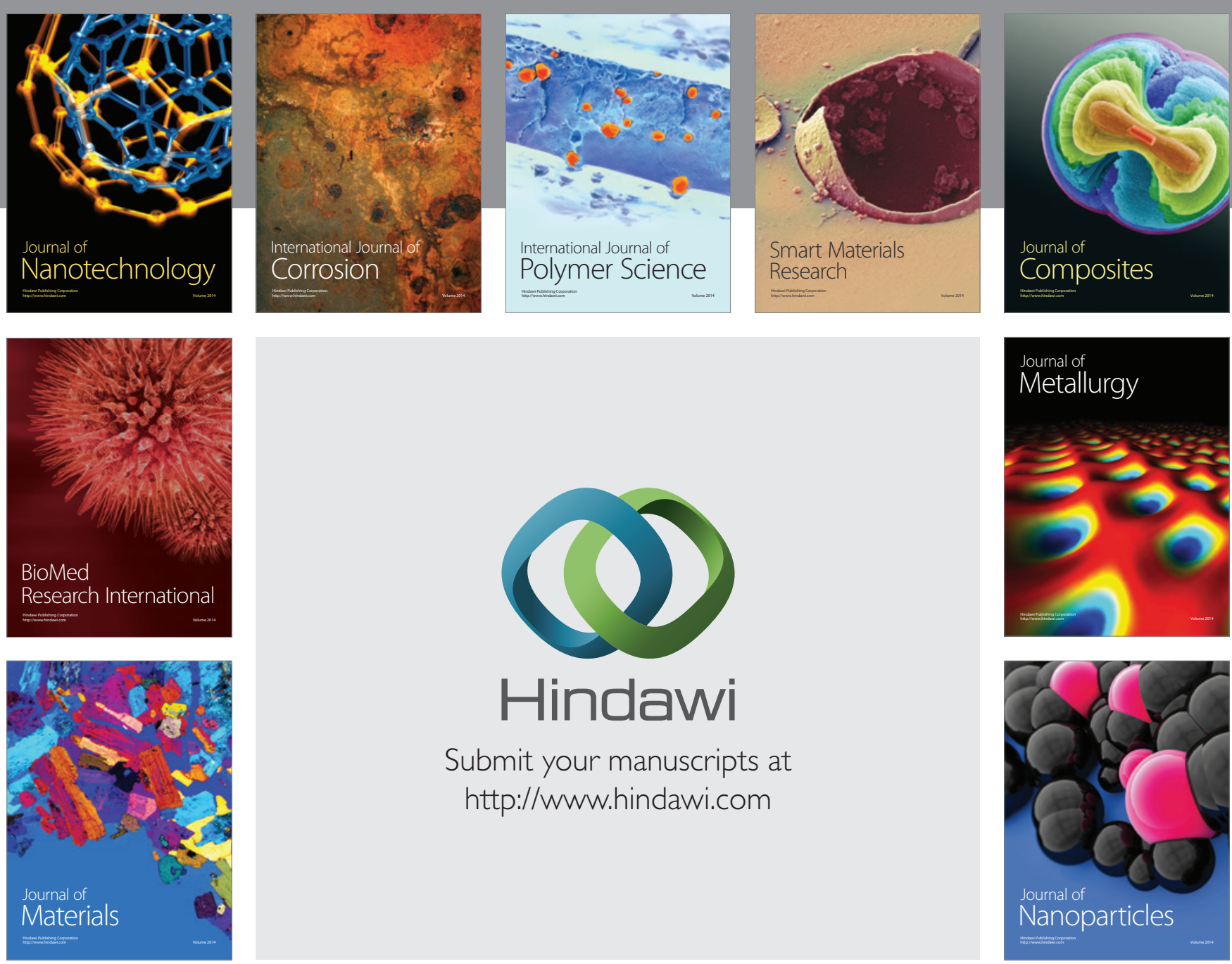

Submit your manuscripts at http://www.hindawi.com
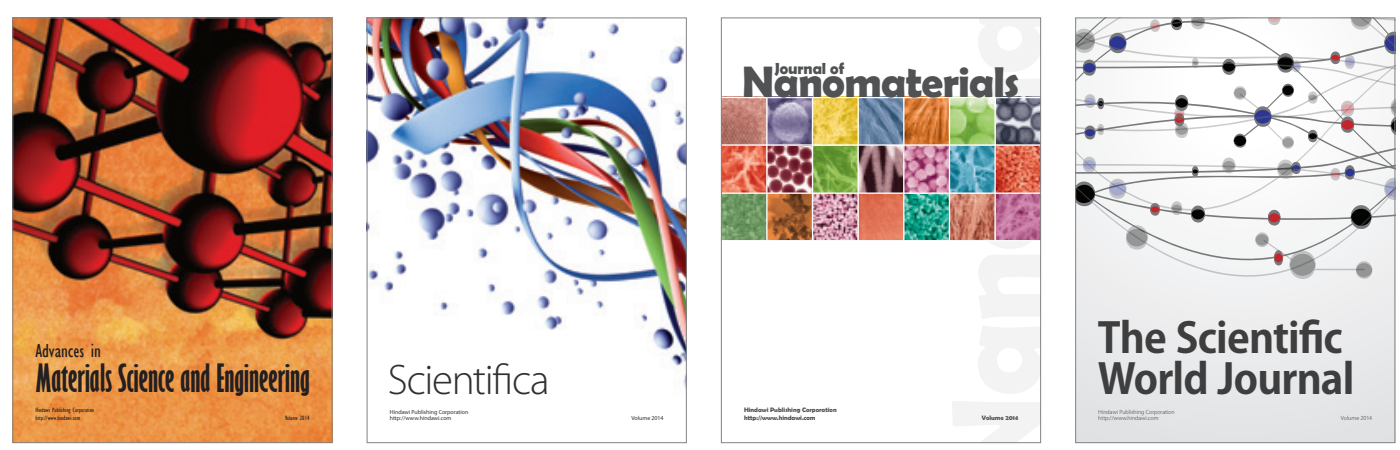

\section{The Scientific World Journal}
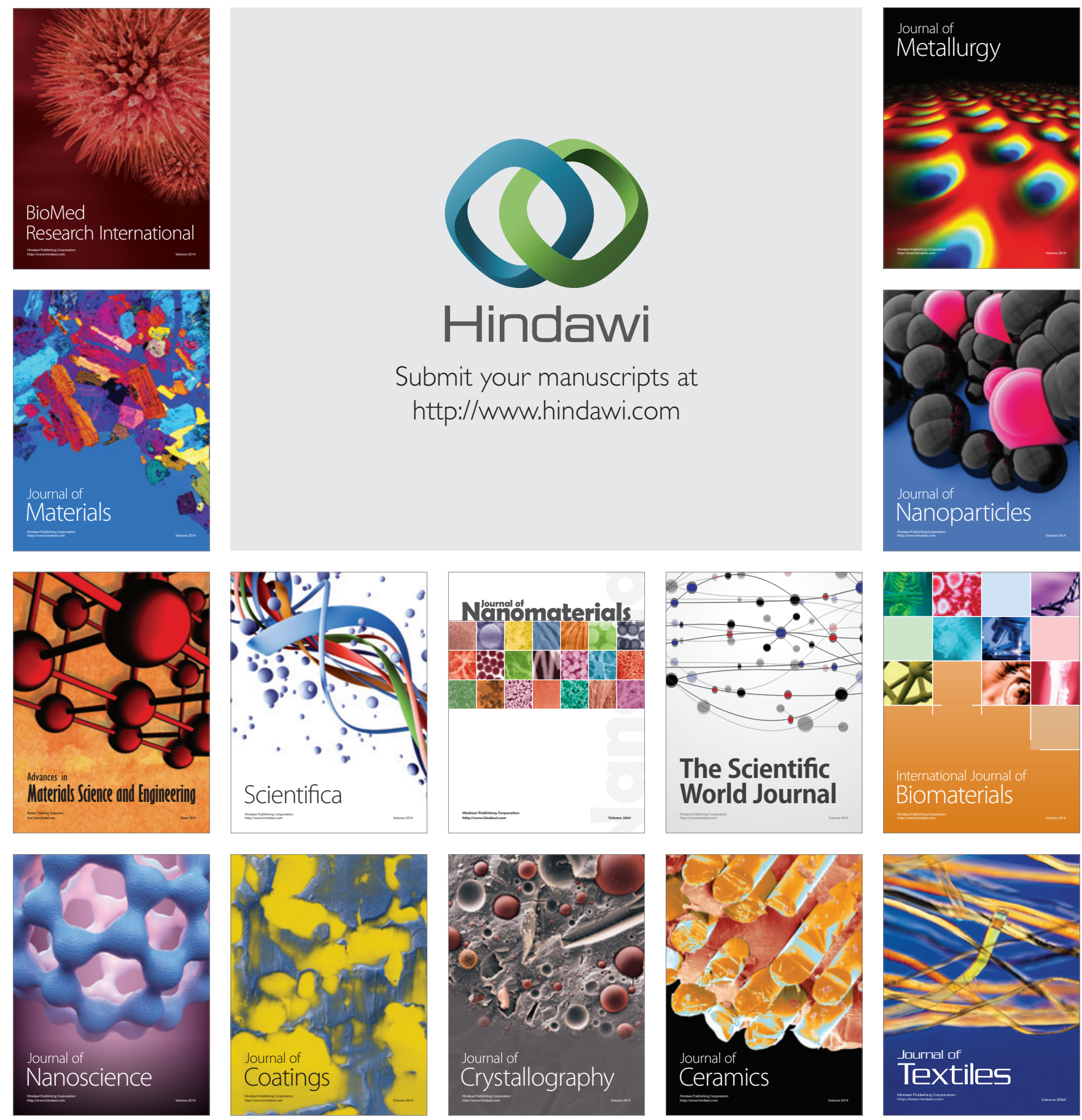